\title{
Nitric Oxide and Superoxide Anion Balance in Rats Exposed to Chronic and Long Term Intermittent Hypoxia
}

\author{
Patricia Siques, ${ }^{1}$ Ángel Luis López de Pablo, ${ }^{2,3}$ Julio Brito, ${ }^{1}$ Silvia M. Arribas, ${ }^{2,3}$ \\ Karen Flores, ${ }^{1}$ Karem Arriaza, ${ }^{1}$ Nelson Naveas, ${ }^{1}$ M. Carmen González, ${ }^{2,3}$ \\ Alexander Hoorntje, ${ }^{2}$ Fabiola León-Velarde, ${ }^{4}$ and M. Rosario López ${ }^{5}$ \\ ${ }^{1}$ Instituto de Estudios de la Salud, Universidad Arturo Prat, Avenida Arturo Prat 2120, 11100939 Iquique, Chile \\ ${ }^{2}$ Departamento de Fisiología, Facultad de Medicina, Universidad Autónoma de Madrid, 28029 Madrid, Spain \\ ${ }^{3}$ Instituto de Investigación Hospital Universitario Gregorio Marañón, 28007 Madrid, Spain \\ ${ }^{4}$ Departamento de Ciencias Biológicas y Fisiológicas, Facultad de Ciencias y Filosofía/IIA, Universidad Peruana Cayetano Heredia, \\ Lima 31, Lima, Peru \\ ${ }^{5}$ Departamento de Medicina Preventiva, Salud Pública y Microbiología, Facultad de Medicina, Universidad Autónoma de Madrid, \\ 28029 Madrid, Spain
}

Correspondence should be addressed to Patricia Siques; psiques@tie.cl

Received 5 December 2013; Accepted 15 January 2014; Published 26 February 2014

Academic Editor: Iveta Bernatova

Copyright (C) 2014 Patricia Siques et al. This is an open access article distributed under the Creative Commons Attribution License, which permits unrestricted use, distribution, and reproduction in any medium, provided the original work is properly cited.

Work at high altitude in shifts exposes humans to a new form of chronic intermittent hypoxia, with still unknown health consequences. We have established a rat model resembling this situation, which develops a milder form of right ventricular hypertrophy and pulmonary artery remodelling compared to continuous chronic exposure. We aimed to compare the alterations in pulmonary artery nitric oxide (NO) availability induced by these forms of hypoxia and the mechanisms implicated. Rats were exposed for 46 days to normoxia or hypobaric hypoxia, either continuous $(\mathrm{CH})$ or intermittent (2 day shifts, $\mathrm{CIH} 2 \mathrm{x} 2)$, and assessed: NO and superoxide anion availability (fluorescent indicators and confocal microscopy); expression of phosphorylated endothelial NO synthase (eNOS), NADPH-oxidase (p22phox), and 3-nitrotyrosine (western blotting); and NADPH-oxidase location (immunohistochemistry). Compared to normoxia, (1) NO availability was reduced and superoxide anion was increased in both hypoxic groups, with a larger effect in $\mathrm{CH}$, (2) eNOS expression was only reduced in $\mathrm{CH}$, (3) NADPH-oxidase was similarly increased in both hypoxic groups, and (4) 3-nitrotyrosine was increased to a larger extent in $\mathrm{CH}$. In conclusion, intermittent hypoxia reduces NO availability through superoxide anion destruction, without reducing its synthesis, while continuous hypoxia affects both, producing larger nitrosative damage which could be related to the more severe cardiovascular alterations.

\section{Introduction}

Exposure to hypoxia, in either chronic or intermittent conditions, is associated with cardiovascular alterations. Hypoxia-related diseases are well characterized in people living at high altitude (chronic hypoxia, $\mathrm{CH}$ ) [1] and in obstructive sleep apnea (OSA), where hypoxic conditions are maintained intermittently for brief periods [2]. Another mode of intermittent hypoxia has arisen as a result of the recent settlements of mines and other activities at high altitude (chronic intermittent hypoxia, $\mathrm{CIH}$ ), where subjects repeatedly ascend from sea level to $3800-4200 \mathrm{~m}$ and work in shifts, being exposed to hypoxia for longer periods than in OSA conditions [3]. The large number of workers under these circumstances, together with the known deleterious cardiovascular effects reported in OSA patients [4], makes it of utmost importance to study the mechanisms implicated in $\mathrm{CIH}$ alterations. Since this condition is a relatively recent phenomenon, studies are still limited and animal models are valuable. We have used an experimental model of $\mathrm{CIH}$, where rats are exposed to hypobaric hypoxia in shifts resembling the human situation [5]. We and others have found that under these experimental conditions the rats develop pulmonary hypertension, pulmonary vascular remodeling, and right 
ventricular hypertrophy $[6,7]$, which are milder compared to rats chronically exposed to hypoxia [8].

Hypoxia-induced pulmonary hypertension and right ventricular hypertrophy are related to pulmonary artery vasoconstriction and vascular remodeling $[9,10]$, endothelial nitric oxide (NO) being an important modulator of these responses [11, 12]. Human and animal studies demonstrate that OSA is associated with reduced NO availability, due to a decreased production or destruction by an excess of reactive oxygen species (ROS) [2] and pulmonary artery vasoconstriction has been suggested to result from imbalance between endothelial vasodilator factors and ROS [13]. NOROS misbalance can also contribute to remodeling process in the pulmonary vasculature, through modification of cell migration, proliferation, dedifferentiation, and apoptosis [14]. We have previously demonstrated that rats exposed to long term $\mathrm{CIH}$ exhibit pulmonary artery remodeling with characteristic features which differ from those found under chronic exposure conditions $[15,16]$. While there are several studies in OSA conditions, to the best of our knowledge, there are no data regarding the effect of hypoxia maintained intermittently during days on NO/ROS balance in the pulmonary vasculature. Therefore, we aimed to analyze the possible alterations under this condition and to compare them with those induced by continuous hypoxic exposure. We have used a rat model mimicking the conditions of subjects working in shifts or permanently living at high altitude.

\section{Materials and Methods}

2.1. Animal Model. Three-month-old male Wistar rats were used. The rats were exposed to $22 \pm 2^{\circ} \mathrm{C}, 12 \mathrm{~h}$ light/dark cycle and were maintained in separate cages, with food made available to them ( $20 \mathrm{~g}$ pellets/day per rat) and water ad libitum. Standard veterinary care was used during all of the experiments following institutional protocols for the study of animals and the procedures used were approved by the Institutional Research Ethics Committee of Universidad Arturo Prat (Chile). The rats were randomly assigned to one of the following groups:

normoxia control group (NX; $n=10)$;

chronic intermittent hypoxia, 2 days under hypobaric hypoxia and 2 days under normobaric normoxia for 46 days $(\mathrm{CIH} 2 \times 2 ; n=10)$;

chronic hypoxia, continuous hypobaric hypoxia for 46 days $(\mathrm{CH} ; n=10)$.

Hypobaric hypoxia was simulated at Universidad Arturo Prat facilities in a hypobaric chamber at 428 Torr, which is equivalent to an altitude of $4600 \mathrm{~m}\left(\mathrm{PO}_{2}=89 \mathrm{mmHg}, \mathrm{PCO}_{2}\right.$ $=0.15 \mathrm{mmHg}$, temperature $22 \pm 2^{\circ} \mathrm{C}$, and humidity $\left.35 \pm 5 \%\right)$. Control (sea level) conditions were $\mathrm{PO}_{2}=159 \mathrm{mmHg}, \mathrm{PCO}_{2}$ $=0.29 \mathrm{mmHg}$, temperature $22 \pm 2^{\circ} \mathrm{C}$, and humidity $35 \pm 5 \%$. The animal model for chronic intermittent hypoxia exposure $(\mathrm{CIH} 2 \mathrm{x} 2)$ has been described previously $[5,8,17]$. This model involves 2 days of hypoxia and 2 days of normoxia over a period of 46 days. We maintained the rats for 46 days, since previous data indicate that the hematological and cardiovascular effects in the rat are maximal between 30 and 45 days of exposure to hypoxia [5]. The $2 \times 2$ regimen was chosen in order to mimic long term exposure to intermittent hypoxic conditions as experienced by human subjects working in shifts at high altitude, which is in the order of days (usually 7-14) [18], and including at least one full circadian cycle. The control group was placed in the same room at sea level during the 46-day period.

All the rats were weighted at day 1 and at day 46 using an Acculab V-1200 electronic balance. At day 46 a blood sample was taken from the tail and hematocrit was measured using a microcentrifuge (Eppendorf AG, Hamburg, Germany). Thereafter, the animals were euthanized with an overdose of anesthesia (Ketamine, $8 \mathrm{mg}$, i.p.) and the heart and the lungs were removed in a block for further dissection.

The heart was cut down and the right ventricle was detached from the heart, leaving in situ the septum portion together with the left ventricle. Both ventricles were weighed in an analytic balance (Acculab V-1200, Illinois, USA) and the ratio between the right ventricle/left ventricle plus the septum weight was used to measure the grade of right ventricular hypertrophy. We did not use total heart weight or right ventricular weight/body weight since we have previously reported that exposure to hypoxia produces alterations in body weight gain [5]. The removed lung was placed in a Petri dish and pulmonary artery branches (4th order) were dissected and stored for further experiments in saline solution $(0.9 \% \mathrm{NaCl})$.

\subsection{Confocal Microscopy}

2.2.1. Determination of NO Availability. Basal NO availability was determined by the fluorescent $\mathrm{NO}$ indicator 4,5-diaminofluorescein diacetate (DAF-2 DA, Sigma) as described previously [19]. Briefly, $3 \mathrm{~mm}$ length pulmonary artery segments were stabilized in physiological salt solution (PSS; $115 \mathrm{mmol} / \mathrm{L} \mathrm{NaCl}, 4.6 \mathrm{mmol} / \mathrm{L} \mathrm{KCl}, 25 \mathrm{mmol} / \mathrm{L}$ $\mathrm{NaHCO}_{3}, 1.2 \mathrm{mmol} / \mathrm{L} \mathrm{KH}_{2} \mathrm{PO}_{4}, 1.2 \mathrm{mmol} / \mathrm{L}, \mathrm{MgSO}_{4}$, and $2.5 \mathrm{mmol} / \mathrm{L} \mathrm{CaCl}_{2}$ ), for $30 \mathrm{~min}$ at $37^{\circ} \mathrm{C}$, and oxygenated with carbogen $\left(95 \% \mathrm{O}_{2}\right.$ and $\left.5 \% \mathrm{CO}_{2}\right)$. Thereafter, they were stained with oxygenated DAF-2 DA solution $(10 \mu \mathrm{mol} / \mathrm{L})$ for $30 \mathrm{~min}$ in the darkness at $37^{\circ} \mathrm{C}$, in a shaking water bath. This experimental procedure in saturated oxygen ensures that $\mathrm{NO}$, rather than $\mathrm{O}_{2}$, is the limiting factor in the reaction and the fluorescence is directly proportional to NO [19]. Negative controls for DAF-2 DA were incubated in $0.1 \mathrm{mmol} / \mathrm{L} \mathrm{L}$ NAME throughout the experimental period. The segments were then washed 3 times for $1 \mathrm{~min}$ each in PSS and fixed in $4 \%(\mathrm{w} / \mathrm{v})$ paraformaldehyde. The segments were cut in rings with a blade and mounted on a slide equipped with a small well made of spacers, filled with mounting medium (Citifluor, Aname, Spain), and covered with a cover glass. The arterial rings were visualized with a Leica TCS SP2 confocal system (Leica Microsystems, Wetzlar, Germany) at Universidad Autónoma de Madrid of Spain facilities using the $488 \mathrm{~nm} / 515 \mathrm{~nm}$ line. $1 \mu \mathrm{m}$ thick serial images $(25 \mu \mathrm{m}$ in total) were captured with a $63 \mathrm{x}$ objective at zoom 2 in 3 
randomly chosen areas of the ring, at identical conditions of brightness, contrast, and laser power for all of the experimental groups. MetaMorph image analysis software (Universal Imaging Co., UK) was used for quantification of fluorescence intensity. Briefly, the serial images were first reconstructed in a confocal projection and fluorescence intensity was quantified in several regions of the smooth muscle cells, where the dye is trapped, avoiding the elastic lamella which is also fluorescent in the same wavelength.

2.2.2. Determination of $\mathrm{O}_{2}{ }^{--}$Availability. Dihydroethidium (DHE, Sigma) was used to determine basal $\mathrm{O}_{2}{ }^{\cdot-}$, as described [19]. Briefly, $3 \mathrm{~mm}$ long pulmonary arteries were stabilized in PSS $\left(30 \mathrm{~min}\right.$ at $\left.37^{\circ} \mathrm{C}\right)$. Thereafter, they were incubated with $3 \mu \mathrm{mol} / \mathrm{L} \mathrm{DHE}$, washed 3 times for $1 \mathrm{~min}$ each in PSS, and fixed in $4 \%(\mathrm{w} / \mathrm{v})$ paraformaldehyde. Negative controls for DHE were incubated in 15 units/mL superoxide dismutase (SOD) throughout the incubation period. The segments were then washed 3 times for $1 \mathrm{~min}$ each in PSS, fixed in 4\% (w/v) paraformaldehyde, cut in rings, and mounted as described above. $1 \mu \mathrm{m}$ thick serial images ( $25 \mu \mathrm{m}$ in total) were captured with a $63 x$ objective at zoom 2 in 3 randomly chosen areas of the ring, at identical conditions of brightness, contrast, and laser power for all of the experimental groups with the $488 \mathrm{~nm} / 590-620 \mathrm{~nm}$ line of the microscope. MetaMorph image analysis software (Universal Imaging Co., UK) was used for quantification of fluorescence intensity, which was located in the nuclei. The serial images were first reconstructed in a confocal projection and fluorescence intensity was quantified in several regions along the ring.

2.2.3. NADPH-Oxidase Detection by Immunohistochemistry. To detect the presence of NADPH oxidase in the adventitial layer, pulmonary arteries were first incubated with the primary antibody of the p22phox subunit of the enzyme (rabbit polyclonal, Santa Cruz Biotechnology, USA) (60 min, 1:200 in saline solution) at room temperature (RT) and then washed with saline solution ( $30 \mathrm{~min}, \mathrm{RT})$. Thereafter, the segments were incubated with the secondary antibody-Alexa Fluor 647 goat anti-rabbit IgG $(\mathrm{H}+\mathrm{L})$ (Invitrogen, Madrid, Spain) (60 min, 1:200, RT in the darkness), followed by washing for $30 \mathrm{~min}, \mathrm{RT}$. Finally, they were incubated with the nuclear dye $4^{\prime}, 6$-diamidino-2-phenylindole (DAPI; 1:500 from a $5 \mathrm{mg} / \mathrm{mL}$ stock; $30 \mathrm{~min}$, RT in the darkness) and washed twice (30 min, RT). The pulmonary arteries were longitudinally sectioned and mounted with the adventitial side facing up, as described above. The arteries were visualized with a Leica TCS confocal system using the $405 \mathrm{~nm}$ excitation/410$475 \mathrm{~nm}$ emission wavelength (DAPI) to locate the cells and the $633 \mathrm{~nm}$ excitation/640-650 $\mathrm{nm}$ emission wavelength (secondary antibody-Alexa 647) to detect the protein. $1 \mu \mathrm{m}$ thick serial images of the adventitial layer $(12 \mu \mathrm{m}$ in total) were captured at both wavelengths with a $40 \mathrm{x}$ objective at zoom 4 from 3 different regions. MetaMorph software was used to count the total number of cells (DAPI positive) and those stained with p22phox. Cell number (DAPI or p22phox positive) was counted always in the same volume which was calculated from the layer thickness $(12 \mu \mathrm{m})$ and the image area at $\times 40$ zoom 4 . We calculated the total number of p22phox positive cells and the relative number of positive cells (positive cells/total cells) in the mentioned volume.

2.3. Western Blot. Western blot was performed according to the standard methods. Briefly, total pulmonary artery tissues were frozen in liquid nitrogen and then homogenized into homogenization buffer containing $50 \mathrm{mM}$ Tris$\mathrm{HCl}, 150 \mathrm{mM} \mathrm{NaCl}, 100 \mathrm{mM}$ NaF, 1\% Triton X-100, $1 \mathrm{mM}$ dithiothreitol, $0.1 \mathrm{mM}$ phenyl methylsulfonyl fluoride, $1 \mathrm{mM}$ leupeptin, $0.02 \mathrm{M}$ Hepes, $10^{-3} \mathrm{M}$ EDTA, $10^{-3} \mathrm{M}$ EGTA, and $20 \%$ glycerol, followed by centrifugation to $10000 \times \mathrm{g}$ by $10 \mathrm{~min}$. Supernatant was removed and protein quantification was carried out by Bradford assay. Equal amount of protein $(25 \mu \mathrm{g})$ was resolved on $7.5-12 \%$ SDS-PAGE and proteins were transferred to a PVDF membrane. The nonspecific binding sites on the membrane were blocked using $5 \%$ nonfat dry milk in TBS-T buffer $(10 \mathrm{mM}$ Tris- $\mathrm{HCl}$, $150 \mathrm{mM} \mathrm{NaCl}, 0.05 \%$ tween 20 , and $\mathrm{pH} 7.4$ ) by 1 hour. Membranes were incubated with primary antibody rabbit polyclonal to PNK (3-nitrotyrosine) and p22phox and goat polyclonal pNOS-3 (phosphorylated form of e-NOS; Santa Cruz Biotechnology, USA) by overnight and washed three times for $15,10,5 \mathrm{~min}$ with TBS-T followed by incubation with horseradish peroxidase-conjugated secondary antibody (1:2000, Santa Cruz Biotechnology, USA) for 1 hour and washed 3 times with TBS-T and once with TBS. Blots were visualized using a West Pico Chemiluminescence System (Pierce, USA) and then analyzed using Image J. Expression levels of p22phox, PNK, and pNOS3 were normalized to $\beta$ actin expression.

2.4. Statistical Analysis. The experimental data were entered into a database and were analyzed using SPSS 17.0 statistical package (SPSS, Inc., Chicago, Ill, USA). Mean, standard deviation, and standard error were calculated for each parameter. Normality was established using the KolmogorovSmirnov test. Statistical analysis of the differences across all testing conditions was established using analysis of variance (ANOVA) of one factor and less significant difference post hoc tests. All of the variables were normally distributed. Statistical significance was established at a $P$ value $<0.05$.

\section{Results}

3.1. Body Weight Gain, Hematocrit, and Right Ventricular Hypertrophy. Body weight at day 1 was not statistically different between experimental groups (NX: $247.8 \pm 16.6 \mathrm{gr}$, CIH2x2: $246.9 \pm 11.2$ gr, and CH: $251.5 \pm 17.2$ gr). While NX rats gained weight over the 46-day period (final body weight $\mathrm{NX}=330 \pm 13.5 \mathrm{~g})$, there was a gradual weight loss in both hypoxic groups (final body weight $\mathrm{CIH} 2 \times 2=206 \pm 8.03 \mathrm{~g}$; $\mathrm{CH}$ $=169 \pm 3.6 \mathrm{~g})$, being significantly smaller compared to NX $(P<0.001)$. Hematocrit at the end of experimental period was significantly higher in $\mathrm{CH}(66 \pm 1.1 \%)$ and in $\mathrm{CIH} 2 \mathrm{x} 2$ $(58 \pm 1.8 \%)$, compared to NX rats $(51 \pm 1.0 \%)(P<0.01)$. $\mathrm{CIH} 2 \times 2$ hematocrit was significantly smaller compared to $\mathrm{CH}(P<0.01)$. Right ventricular weight/total heart weight 

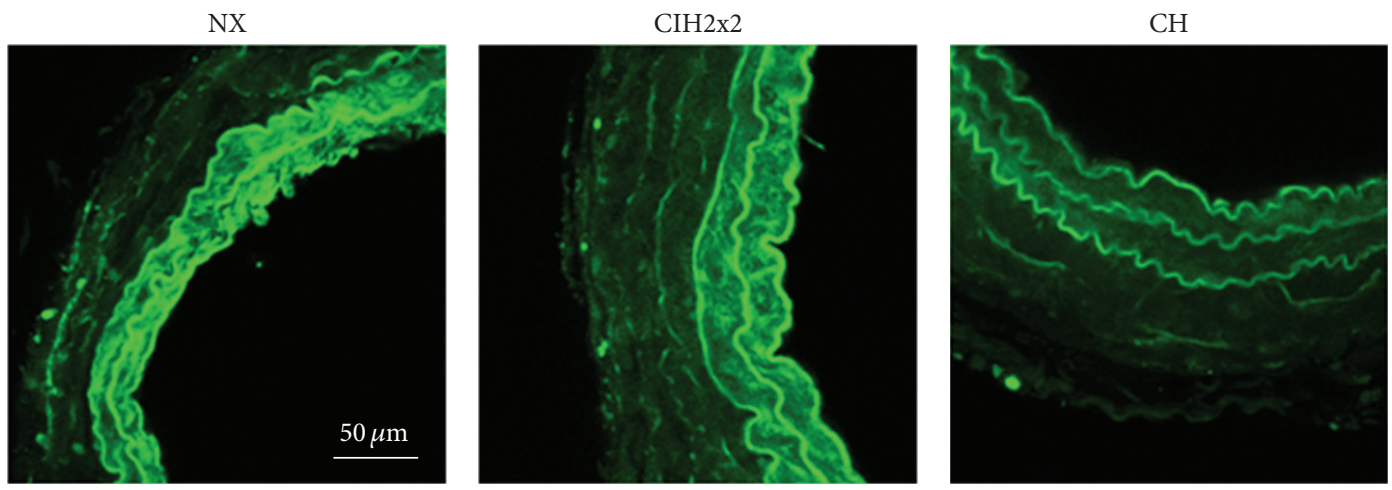

(a)

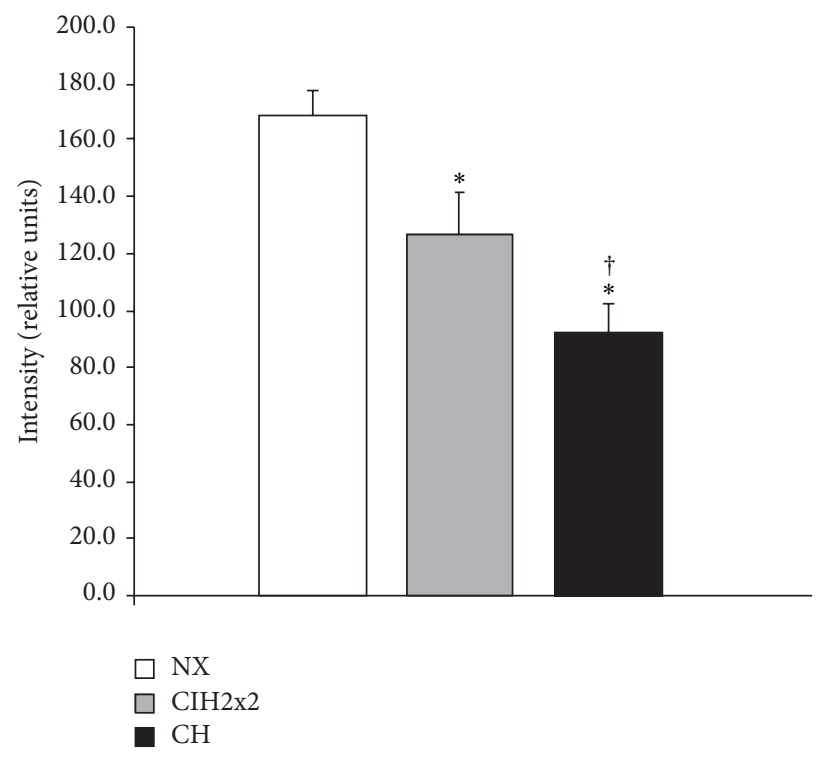

(b)

Figure 1: DAF-2 DA intensity levels in pulmonary arteries from rats exposed to normoxia (NX, $n=10)$, intermittent hypoxia $(\mathrm{CIH} 2 \mathrm{x} 2$, $n=10)$, or chronic hypoxia $(\mathrm{CH}, n=10)$. (a) Representative examples of projections obtained from confocal microscopy images $(\times 40$ zoom 2). (b) Quantitative analysis; $n$ represents the number of animals; ${ }^{*} P<0.05$ compared to NX; ${ }^{\dagger} P<0.05$ compared to CIH $2 \times 2$.

was smaller in NX $(\mathrm{NX}=0.23 \pm 0.02 ; P<0.01)$ compared to $\mathrm{CIH} 2 \mathrm{x} 2$ rats $(0.34 \pm 0.02)$ and $\mathrm{CH}$ group $(0.40 \pm 0.02)$, which was also significantly larger compared to intermittent exposure group $(P<0.05)$.

3.2. NO Availability. The fluorescence emitted by DAF-2 DA was located in the cytoplasm of smooth muscle cells. Pulmonary arteries from NX group exhibited a significantly higher DAF-2 DA emitted fluorescence compared to both hypoxic groups, suggesting a larger basal NO availability [19]. Fluorescence was significantly lower in $\mathrm{CH}$ rats compared to CIH2x2 (Figure 1).

3.3. $\mathrm{O}_{2}{ }^{--}$Availability. DHE fluorescence was located in the cell nuclei. NX rats showed a smaller level of fluorescence intensity compared to both hypoxic groups, being higher in $\mathrm{CH}$ compared to $\mathrm{CIH} 2 \times 2$ (Figure 2).
3.4. Phosphorylated eNOS, p22phox, and 3-Nitrotyrosine Expression. Expression of the phosphorylated form of eNOS was significantly reduced in $\mathrm{CH}$ compared to NX. The expression levels in $\mathrm{CIH} 2 \mathrm{x} 2$ were not statistically different from NX (Figure 3(a)).

p22phox expression was scarcely detectable in pulmonary arteries from NX but was largely increased in both hypoxic rats, without differences between $\mathrm{CH}$ and $\mathrm{CIH} 2 \mathrm{x} 2$ groups (Figure 3(b)).

3-Nitrotyrosine expression, a marker of nitrosative damage, was significantly elevated in pulmonary arteries from hypoxic rats compared to NX, being significantly larger in $\mathrm{CH}$ compared to CIH2x2 (Figure 3(c)).

3.5. p22phox Location in the Adventitia. The total number of adventitial cells, quantified by the nuclear dye DAPI in a fixed volume, was significantly higher in pulmonary arteries from 

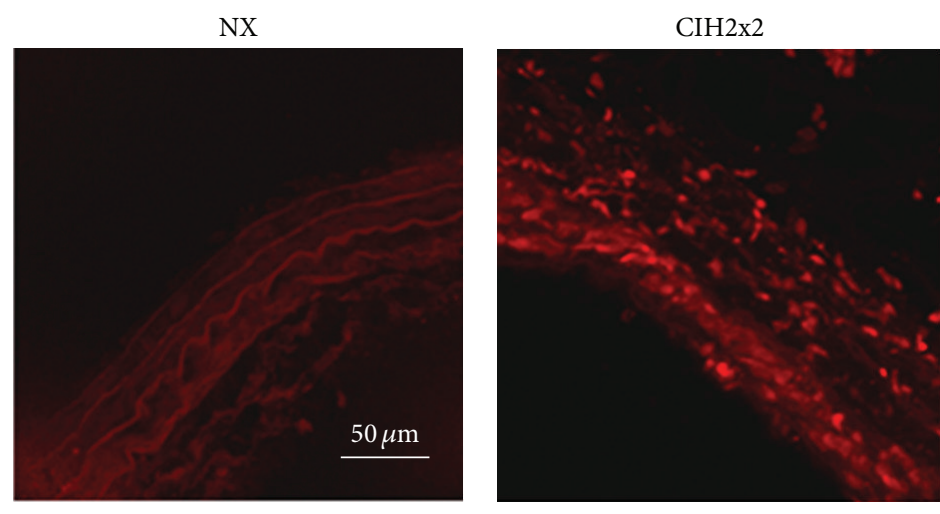

(a)
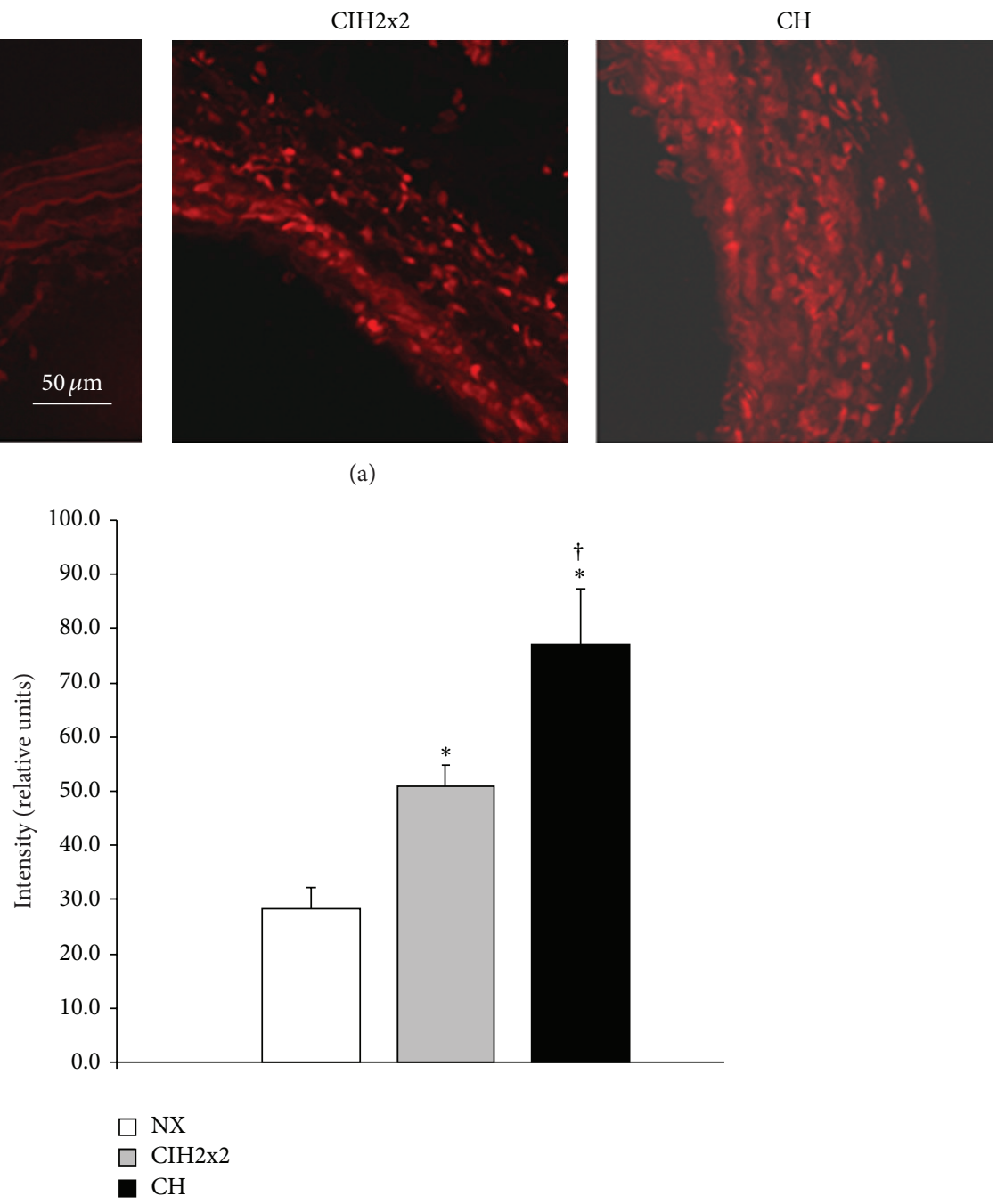

(b)

Figure 2: DHE intensity levels in pulmonary arteries from rats exposed to normoxia (NX, $n=10)$, intermittent hypoxia (CIH2x2, $n=10)$, or chronic hypoxia $(\mathrm{CH}, n=10)$. (a) Representative examples of projections obtained from confocal microscopy images $(\times 40$ zoom 2$)$. (b) Quantitative analysis; $n$ represents the number of animals; ${ }^{*} \mathrm{P}<0.05$ compared to $\mathrm{NX} ;{ }^{\dagger} \mathrm{P}<0.05$ compared to $\mathrm{CIH} 2 \mathrm{x} 2$.

both hypoxic rats $(\mathrm{CIH} 2 \times 2=144.7 \pm 13.2 ; \mathrm{CH}=157.1 \pm 9.7)$ compared to control $(\mathrm{NX}=74.9 \pm 2.6, P<0.001)$.

P22phox staining was observed in the three experimental groups and was located around some of the adventitial cells. Pulmonary arteries from hypoxic rats exhibited a larger level of staining compared to NX (Figure 4(a)). Both total and relative numbers of $\mathrm{p} 22 \mathrm{phox}$ positive cells were significantly larger in the adventitial layer of hypoxic rats compared to NX, with no statistical difference between $\mathrm{CIH} 2 \times 2$ and $\mathrm{CH}$ rats (Figure 4(b)).

\section{Discussion}

The main findings of the current study are that exposure to chronic intermittent hypoxia reduces NO availability in the pulmonary vasculature. This decrease is likely due to NO destruction by $\mathrm{O}_{2}{ }^{--}$, generated by NADPH-oxidase, while eNOS is not altered. On the other hand, in continuous exposure to hypoxia, NO availability is further reduced, through the combination of diminished NO synthesis and increased destruction. In consequence, chronic hypoxia produces larger nitrosative damage compared to intermittent exposure, which likely contributes to the higher impact on pulmonary artery remodeling and right ventricular hypertrophy (Figure 5 summarizes these results).

The present data confirmed that hypoxia induced weight loss, right ventricular hypertrophy, and hematocrit increase, as previously described by us [8] and others [6, 7]. We have also described remodeling of the pulmonary vasculature $[15,16]$, these alterations being less severe under intermittent exposure. We aimed to assess if the above mentioned cardiovascular alterations are linked to NO/ROS misbalance. To the best of our knowledge, there is virtually no information in long term intermittent hypoxia conditions, the majority of evidence coming from OSA studies [20], where low oxygen levels are maintained for very brief periods. 

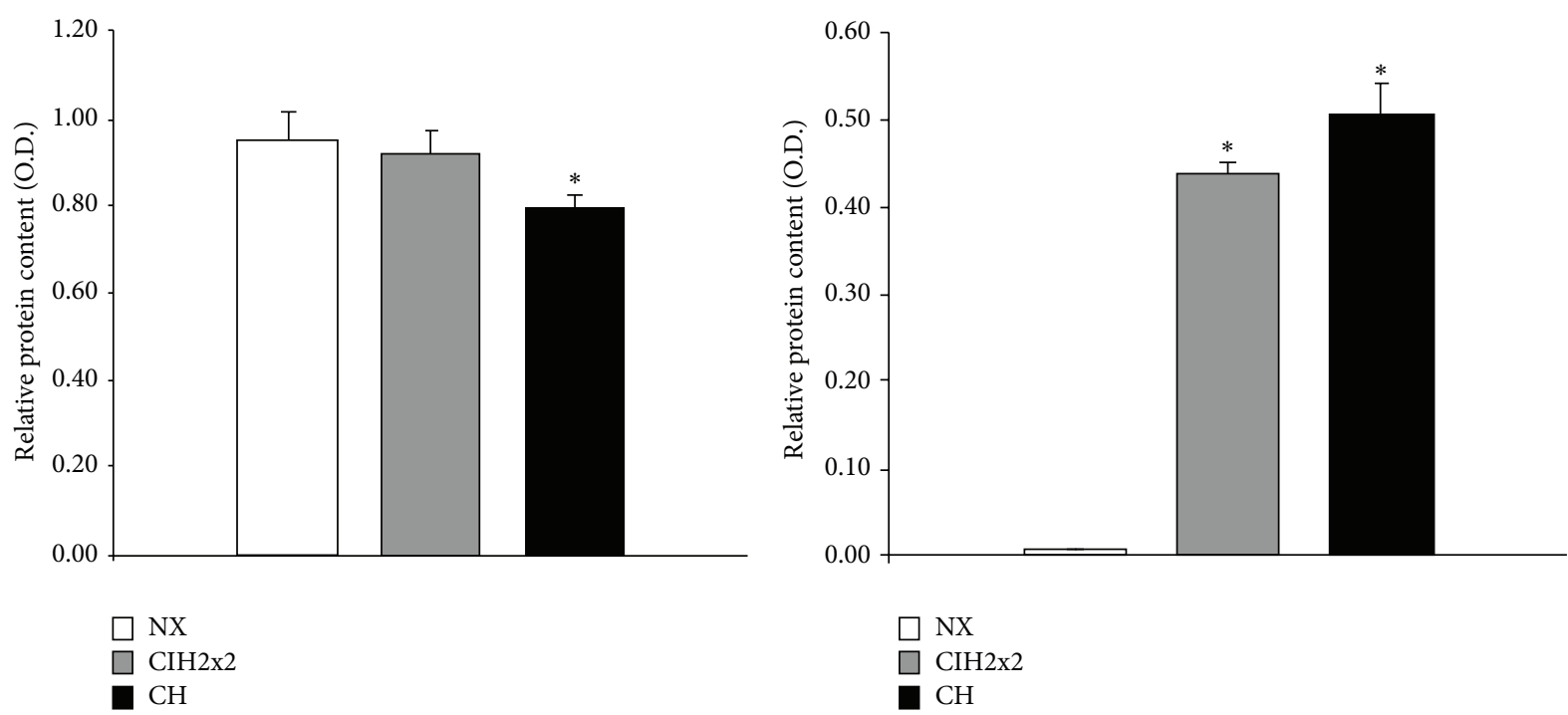

(a) eNOS

(b) p22phox
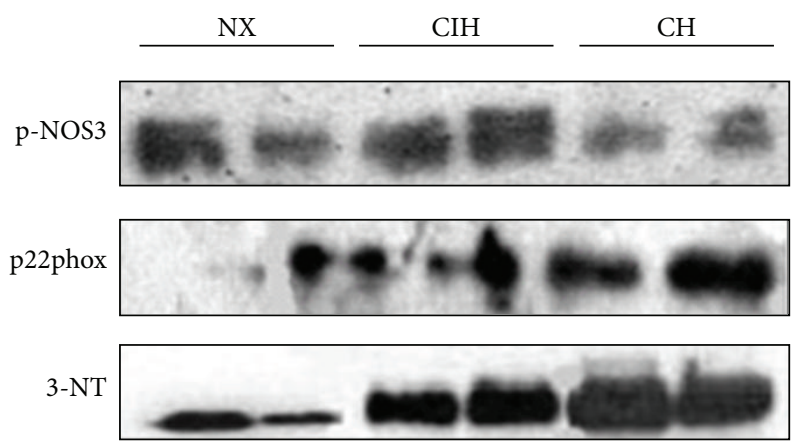

$\beta$-Actin

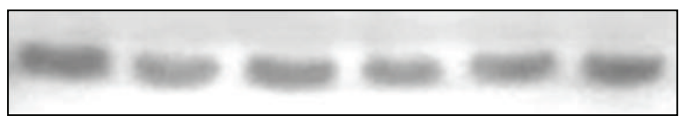

$$
\begin{aligned}
& \square \mathrm{NX} \\
& \square \mathrm{CIH} 2 \times 2 \\
& \square \mathrm{CH}
\end{aligned}
$$

(c) 3-Nitrotyrosine

(d) Representative examples

FIGURE 3: Western blot analysis of: (a) phosphorylated eNOS, (b) p22phox, and (c) 3-nitrotyrosine from pulmonary arteries of rats exposed to normoxia (NX, $n=9$ ), intermittent hypoxia $(\mathrm{CIH} 2 \times 2, n=10)$, or chronic hypoxia $(\mathrm{CH}, n=10)$. (d) Representative examples. $n$ represents the number of animals; ${ }^{*} P<0.05$ compared to $\mathrm{NX} ;{ }^{\dagger} P<0.05$ compared to $\mathrm{CIH} 2 \mathrm{x} 2$.

We focused on NO, a key factor for pulmonary artery resistance [12], since diminished NO availability likely affects both pulmonary artery structure and function. Furthermore, studies on rodents have revealed that intermittent exposure to hypoxia is associated with NO reduction in the systemic and cerebral vasculature [21,22]. Decreased NO availability in the pulmonary vasculature can be the result of a reduced production by eNOS and/or an increased destruction by ROS, particularly $\mathrm{O}_{2}{ }^{--}$, which has been implicated in hypoxic pulmonary vasoconstriction $[13,23-25]$. To determine NO availability, we used DAF-2 DA, a fluorescent indicator directly proportional to the amount of NO [26, 27]. Using confocal microscopy and image analysis software, we have previously demonstrated that this method is sufficiently sensitive for the quantification of basal $\mathrm{NO}$ in resistance and conduit arteries [19, 28, 29]. Continuous hypoxia induced a larger reduction of $\mathrm{NO}$ availability, compared to intermittent exposure. This can be explained by a reduced NO production, as suggested by the decreased expression of phosphorylated eNOS - the active form of the enzyme-found in chronic hypoxia only. The lack of effect of intermittent exposure could be explained by the functional "on-off" (hypoxia-normoxia) switch [30] which is not able to induce downregulation of the NO biosynthetic machinery.

Reduced NO availability in hypoxic conditions seems also to be related to $\mathrm{NO}$ destruction by $\mathrm{O}_{2}{ }^{--}$. This is 

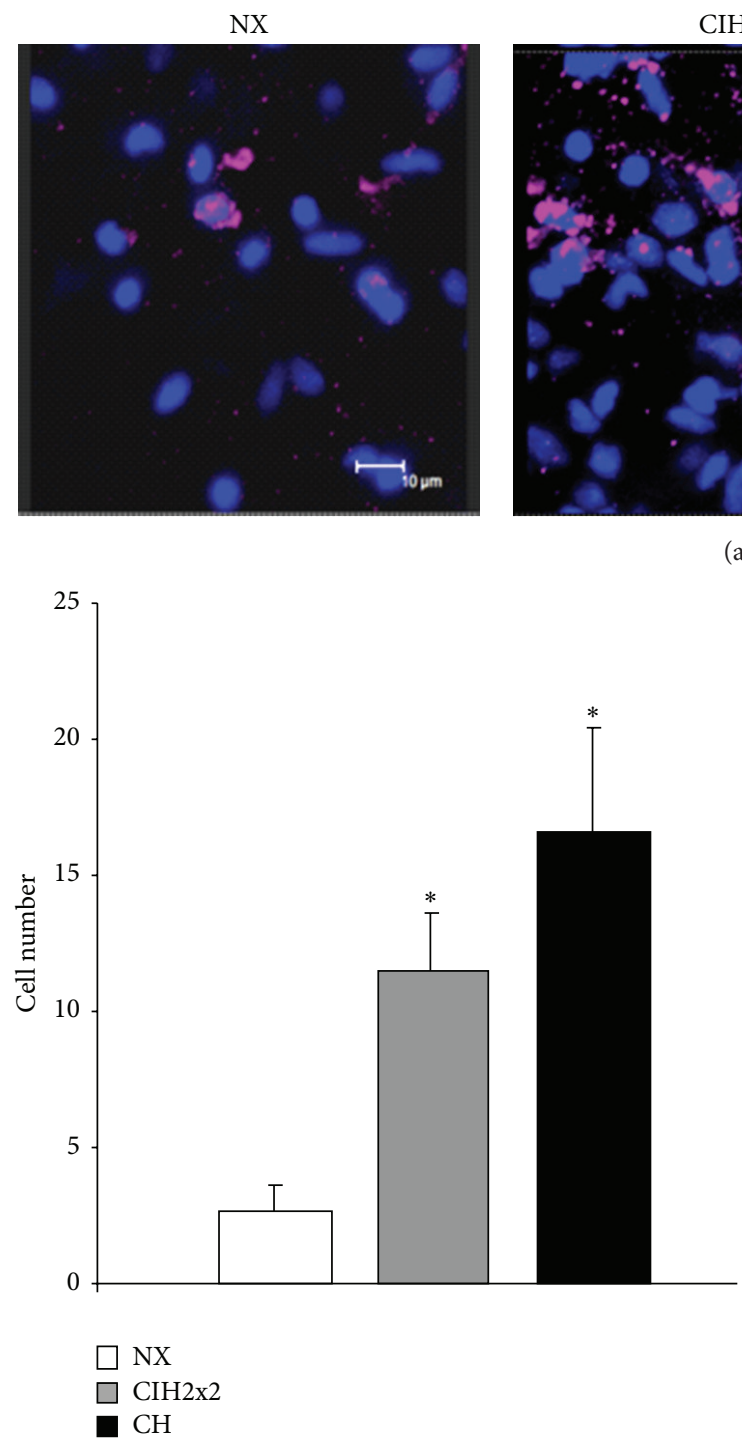

$\mathrm{CIH} 2 \mathrm{x} 2$

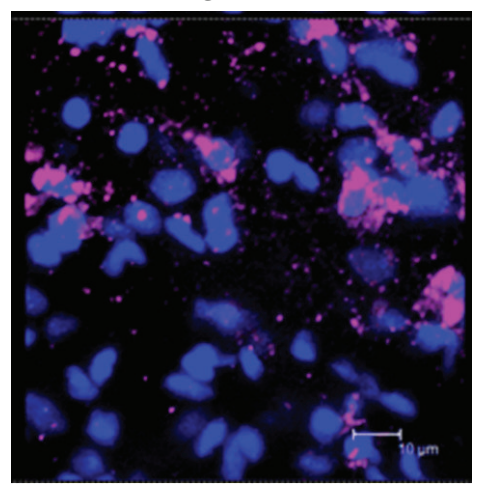

(a)
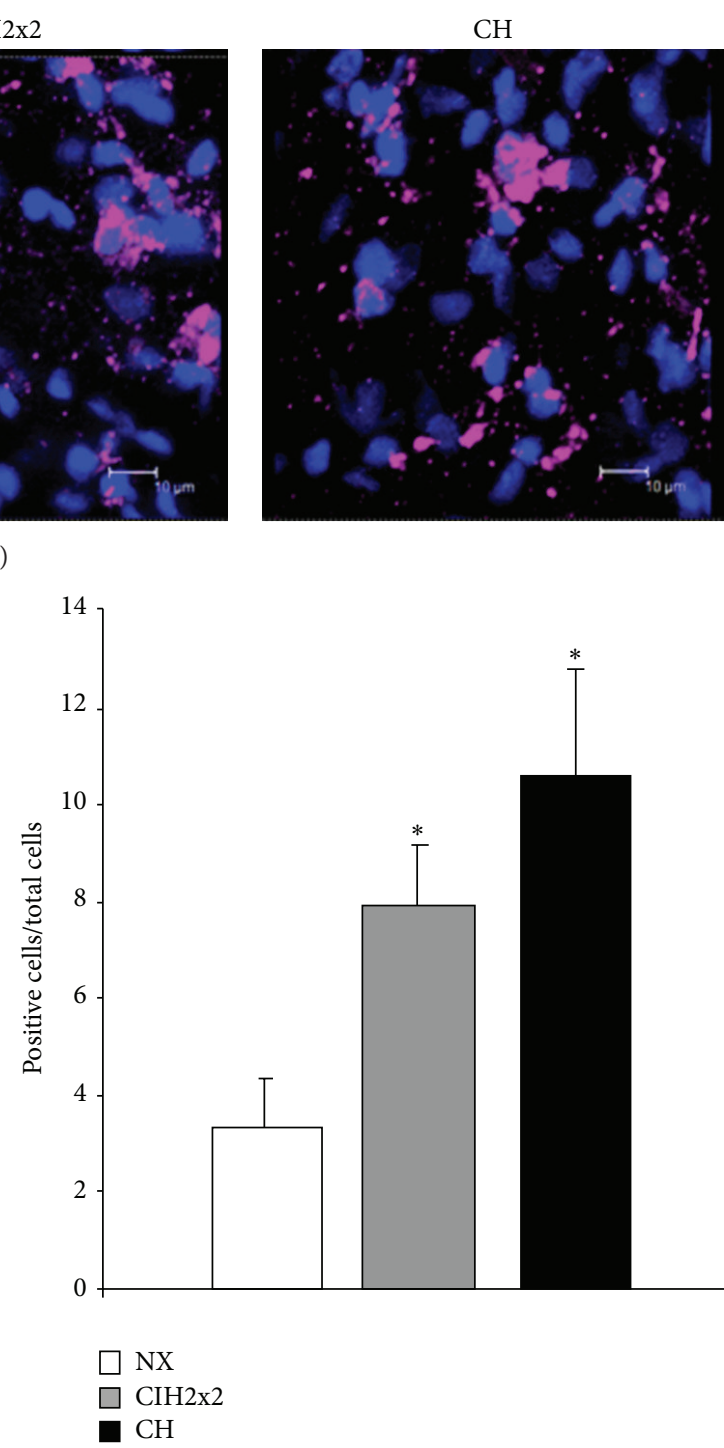

(b) p22phox positive cells

FIGURE 4: Immunohistochemical detection of p22phox positive cells in the adventitia of pulmonary arteries from rats exposed to normoxia (NX, $n=10)$, intermittent hypoxia ( $\mathrm{CIH} 2 \times 2, n=10)$, or chronic hypoxia $(\mathrm{CH}, n=10)$. (a) Representative examples of projections obtained from confocal microscopy images ( $\times 40$ zoom 4 ). (b) Quantitative analysis; $n$ represents the number of animals; ${ }^{*} P<0.05$ compared to NX.

suggested by the increased superoxide anion production found in $\mathrm{CIH} 2 \times 2$ and $\mathrm{CH}$ pulmonary arteries, similarly to data described in an OSA rat model [31]. Superoxide anion levels were even higher in continuous compared to intermittent hypoxia, suggesting that continuous exposure further stimulates the enzymatic systems responsible for ROS synthesis. In the vascular wall, several enzymes produce $\mathrm{O}_{2}{ }^{\bullet-}$, $\mathrm{NADPH}$ oxidase being the main system in the pulmonary vasculature [13, 32]. We found a remarkable expression of this enzyme-confirmed by immunohistochemistry-in both $\mathrm{CH}$ and $\mathrm{CIH} 2 \times 2$, while it was very low in normoxic rats. The important role of this enzyme in intermittent hypoxia has been previously demonstrated in NADPH-oxidase knockout mice exposed to OSA [33]. Our data show that $\mathrm{O}_{2}{ }^{--}$ levels were larger in continuous compared to intermittent hypoxia, despite the similar p22phox expression in both groups. This could be explained by $\mathrm{O}_{2}{ }^{--}$production by xanthine oxidase, as suggested in OSA patients and animal models $[34,35]$. Since it has been reported that, under hypoxic conditions, $\mathrm{O}_{2}{ }^{--}$generated by xanthine oxidase is very small [36], alternatively, $\mathrm{O}_{2}{ }^{--}$can be produced by "uncoupled" dysfunctional eNOS, which can be induced by peroxynitrite [37]. We did not measure peroxynitrite directly but quantified 3-nitrotyrosine, which is currently accepted as evidence of peroxynitrite generation. The larger content of 3-nitrotyrosine found in $\mathrm{CH}$ suggests that eNOS uncoupling can contribute to larger $\mathrm{O}_{2}{ }^{--}$production found in continuous hypoxic conditions compared to intermittent conditions, despite the similar NADPH oxidase expression in both groups. 


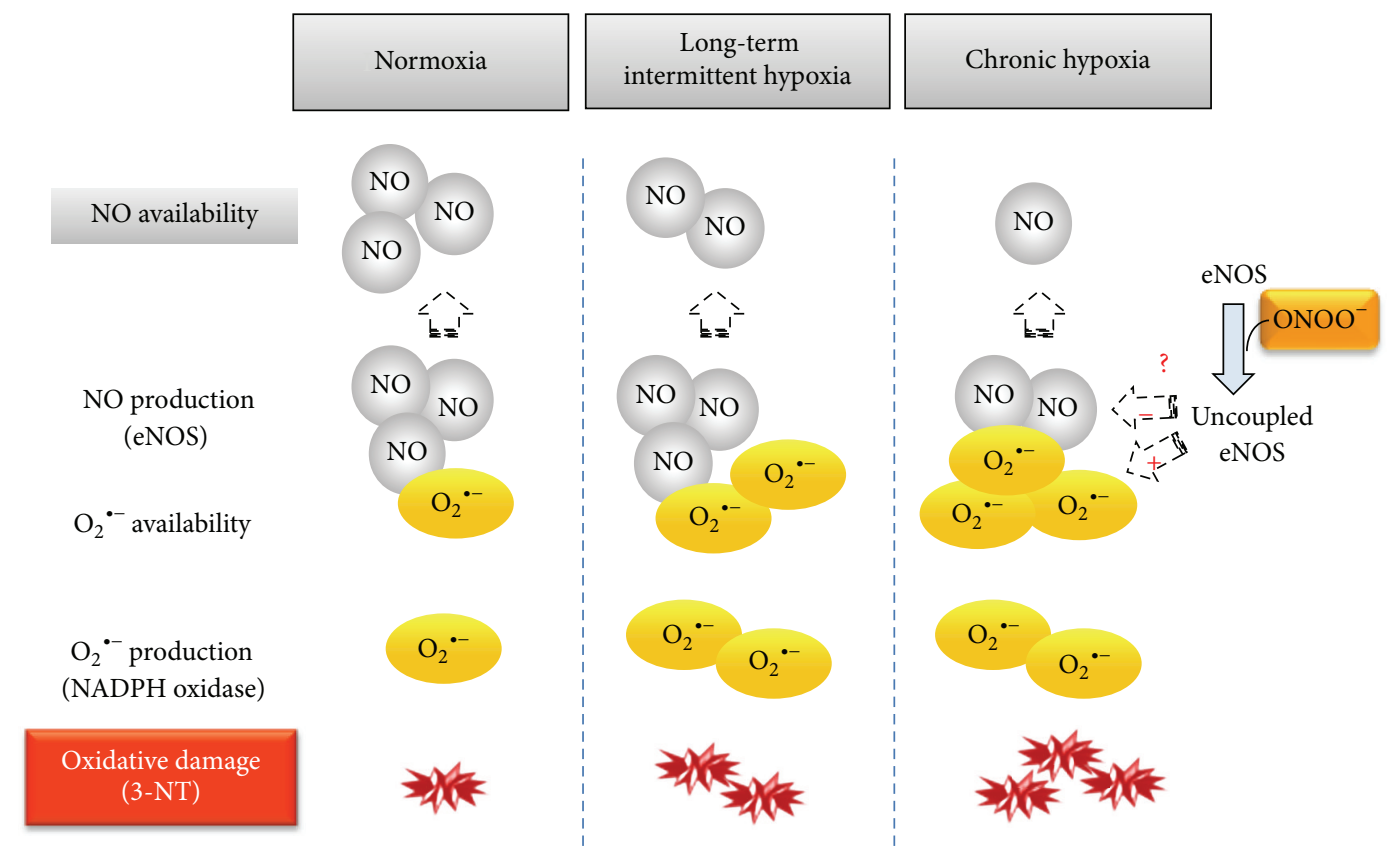

FIGURE 5: Schematic diagram showing the main results and the proposed mechanism implicated in the $\mathrm{NO} / \mathrm{O}_{2}{ }^{--}$misbalance induced by chronic and intermittent hypoxia.

Oxidative-nitrosative stress is associated with vascular remodeling in hypoxia-induced pulmonary hypertension [38]. We have previously found several signs of remodeling in pulmonary arteries from $\mathrm{CH}$ and $\mathrm{CIH} 2 \times 2$ rats, including wall hypertrophy due to increased smooth muscle and adventitial cells $[15,16]$. Adventitial NADPH oxidase has been described to be involved in pulmonary artery adventitial fibroblasts proliferation $[39,40]$ and seems to be a primary site of superoxide anion production in the vessel wall [41-43]. We found that chronic or intermittent hypoxia substantially increased adventitial cell number together with a larger percentage of NADPH-positive cells. Moreover, we [44] and others [43] have previously demonstrated that adventitia is a key layer regarding NO inactivation by ROS. Since NO is an antiproliferative agent, we suggest that an imbalance between $\mathrm{NO} / \mathrm{O}_{2}{ }^{--}$can be linked to the vascular remodeling process under continuous or intermittent hypoxic exposure.

It was beyond the scope of this study to investigate the mechanisms implicated in hypoxia-induced NO/ROS disbalance. However, we can speculate on the possible role of inflammation. Alveolar hypoxia produces widespread systemic inflammation [45] and it also promotes the development of a pulmonary artery chronic inflammatory microenvironment [46]. We also have evidence of infiltrated macrophages in pulmonary arteries from $\mathrm{CH}$ and $\mathrm{CIH} 2 \mathrm{x} 2$ (unpublished results), suggesting that local inflammation in the vascular wall might contribute to the NO/ROS disbalance. In support of this hypothesis, there is evidence that tumor necrosis factor- $\alpha$ can reduce eNOS expression and activity in pulmonary arteries [47]. Moreover, inflammation associated with macrophage infiltration can also contribute to ROS generation through stimulation of NADPH oxidase expression, as previously found in the carotid body under intermittent hypoxic conditions [48].
In conclusion, the present study suggests that hypobaric hypoxia under intermittent conditions reduces NO availability due to destruction by superoxide anion, without affecting NO synthesis, while continuous exposure is associated with both increased degradation and reduced $\mathrm{NO}$ production. The oxidative-nitrosative stress induced by long term intermittent hypoxia might participate in the observed cardiovascular structural alterations but represents a milder form of damage compared to continuous exposure. These data suggest that the alterations in oxidative status of humans chronically or intermittently exposed to high altitude need to be evaluated, in order to improve the associated cardiovascular alterations.

\section{Conflict of Interests}

There is no conflict of interests.

\section{Funding}

This work was funded by GORE-TARAPACA (BIP 30125349-

0) and ALTMEDFIS (CYTED 213RT0478) Grants.

\section{References}

[1] F. León-Velarde, M. Maggiorini, J. T. Reeves et al., "Consensus statement on chronic and subacute high altitude diseases," High Altitude Medicine and Biology, vol. 6, no. 2, pp. 147-157, 2005.

[2] R. Dumitrascu, J. Heitmann, W. Seeger, N. Weissmann, and R. Schulz, "Obstructive sleep apnea, oxidative stress and cardiovascular disease: lessons from animal studies," Oxidative Medicine and Cellular Longevity, vol. 2013, Article ID 234631, 7 pages, 2013. 
[3] J.-P. Richalet, M. V. Donoso, D. Jiménez et al., "Chilean miners commuting from sea level to $4500 \mathrm{~m}$ : a prospective study," High Altitude Medicine and Biology, vol. 3, no. 2, pp. 159-166, 2002.

[4] G. E. Foster, J. V. Brugniaux, V. Pialoux et al., "Cardiovascular and cerebrovascular responses to acute hypoxia following exposure to intermittent hypoxia in healthy humans," Journal of Physiology, vol. 587, no. 13, pp. 3287-3299, 2009.

[5] P. Siqués Lee, J. Brito, F. León-Velarde et al., "Time course of cardiovascular and hematological responses in rats exposed to chronic intermittent hypobaric hypoxia $(4600 \mathrm{~m})$," High Altitude Medicine and Biology, vol. 7, no. 1, pp. 72-80, 2006.

[6] A. F. Corno, G. Milano, S. Morel et al., "Hypoxia: unique myocardial morphology?" Journal of Thoracic and Cardiovascular Surgery, vol. 127, no. 5, pp. 1301-1308, 2004.

[7] M. McGuire and A. Bradford, "Chronic intermittent hypoxia increases haematocrit and causes right ventricular hypertrophy in the rat," Respiration Physiology, vol. 117, no. 1, pp. 53-58, 1999.

[8] J. Brito, P. Siqués, F. León-Velarde et al., "Varying exposure regimes to long term chronic intermittent hypoxia exert different outcomes and morphological effects on Wistar rats at 4600 m," Toxicological and Environmental Chemistry, vol. 90, no. 1, pp. 169-179, 2008.

[9] A. G. Durmowicz and K. R. Stenmark, "Mechanisms of structural remodeling in chronic pulmonary hypertension," Pediatrics in Review, vol. 20, no. 11, pp. e91-e102, 1999.

[10] N. Sommer, A. Dietrich, R. T. Schermuly et al., "Regulation of hypoxic pulmonary vasoconstriction: basic mechanisms," European Respiratory Journal, vol. 32, no. 6, pp. 1639-1651, 2008.

[11] M. S. Wolin, S. A. Gupte, C. J. Mingone, B. H. Neo, Q. Gao, and M. Ahmad, "Redox regulation of responses to hypoxia and NO-cGMP signaling in pulmonary vascular pathophysiology," Annals of the New York Academy of Sciences, vol. 1203, pp. 126$132,2010$.

[12] W. Steudel, M. Scherrer-Crosbie, K. D. Bloch et al., "Sustained pulmonary hypertension and right ventricular hypertrophy after chronic hypoxia in mice with congenital deficiency of nitric oxide synthase," Journal of Clinical Investigation, vol. 101, no. 11, pp. 2468-2477, 1998.

[13] G. Frazziano, H. C. Champion, and P. J. Pagano, "NADPH oxidase-derived ROS and the regulation of pulmonary vessel tone," The American Journal of Physiology, vol. 302, no. 11, pp. H2166-H2177, 2012.

[14] K. K. Griendling and M. Ushio-Fukai, "Reactive oxygen species as mediators of angiotensin II signaling," Regulatory Peptides, vol. 91, no. 1-3, pp. 21-27, 2000.

[15] M. C. González, "Confocal Microscopy as New Tool for the Study of Pulmonary Artery Remodelling at a Cellular Level in Rats Exposed to Chronic Hypobaric Hypoxia," vol. 11, pp. 262, 2010.

[16] P. Siques, "Structural changes in pulmonary artery of exposed rats to chronic intermittent hypobaric hypoxia," High Altitude Medicine and Biology, vol. 11, article 290, 2010.

[17] R. Germack, F. Leon-Velarde, R. Valdes De La Barra, J. Farias, G. Soto, and J. P. Richalet, "Effect of intermittent hypoxia on cardiovascular function, adrenoceptors and muscarinic receptors in Wistar rats," Experimental Physiology, vol. 87, no. 4, pp. 453460, 2002.

[18] J. Brito, P. Siqués, F. León-Velarde, J. J. De La Cruz, V. López, and R. Herruzo, "Chronic intermittent hypoxia at high altitude exposure for over 12 years: assessment of hematological, cardiovascular, and renal effects," High Altitude Medicine and Biology, vol. 8, no. 3, pp. 236-244, 2007.

[19] J. M. González, B. Somoza, M. V. Conde, M. S. FernándezAlfonso, M. C. González, and S. M. Arribas, "Hypertension increases middle cerebral artery resting tone in spontaneously hypertensive rats: role of tonic vasoactive factor availability," Clinical Science, vol. 114, no. 9-10, pp. 651-659, 2008.

[20] Z. Wang, A. Y. Li, Q. H. Guo et al., "Effects of cyclic intermittent hypoxia on ET-1 responsiveness and endothelial dysfunction of pulmonary arteries in rats," PLoS ONE, vol. 8, no. 3, Article ID e58078, 2013.

[21] Z. Tahawi, N. Orolinova, I. G. Joshua, M. Bader, and E. C. Fletcher, "Altered vascular reactivity in arterioles of chronic intermittent hypoxic rats," Journal of Applied Physiology, vol. 90, no. 5, pp. 2007-2000, 2001.

[22] S. A. Phillips, E. B. Olson, B. J. Morgan, and J. H. Lombard, "Chronic intermittent hypoxia impairs endotheliumdependent dilation in rat cerebral and skeletal muscle resistance arteries," The American Journal of Physiology, vol. 286, no. 1, pp. H388-H393, 2004.

[23] D. C. Irwin, J. M. McCord, E. Nozik-Grayck et al., "A potential role for reactive oxygen species and the HIF- $1 \alpha$-VEGF pathway in hypoxia-induced pulmonary vascular leak," Free Radical Biology and Medicine, vol. 47, no. 1, pp. 55-61, 2009.

[24] N. Weissmann, R. T. Schermuly, H. A. Ghofrani et al., "Hypoxic pulmonary vasoconstriction: triggered by an increase in reactive oxygen species?" Novartis Foundation Symposium, vol. 272, pp. 196-208, 2006.

[25] N. Weissmann, S. Zeller, R. U. Schäfer et al., "Impact of mitochondria and NADPH oxidases on acute and sustained hypoxic pulmonary vasoconstriction," The American Journal of Respiratory Cell and Molecular Biology, vol. 34, no. 4, pp. 505513, 2006.

[26] H. Kojima, N. Nakatsubo, K. Kikuchi et al., "Direct evidence of NO production in rat hippocampus and cortex using a new fluorescent indicator: DAF-2 DA," NeuroReport, vol. 9, no. 15, pp. 3345-3348, 1998.

[27] F.-X. Yi, A. Y. Zhang, W. B. Campbell, A.-P. Zou, C. Van Breemen, and P.-L. Li, "Simultaneous in situ monitoring of intracellular $\mathrm{Ca} 2+$ and $\mathrm{NO}$ in endothelium of coronary arteries," The American Journal of Physiology, vol. 283, no. 6, pp. $\mathrm{H} 2725-\mathrm{H} 2732,2002$.

[28] S. M. Arribas, C. J. Daly, M. C. González, and J. C. Mcgrath, "Imaging the vascular wall using confocal microscopy," Journal of Physiology, vol. 584, no. 1, pp. 5-9, 2007.

[29] B. Somoza, F. Abderrahim, J. M. González et al., "Shortterm treatment of spontaneously hypertensive rats with liver growth factor reduces carotid artery fibrosis, improves vascular function, and lowers blood pressure," Cardiovascular Research, vol. 69, no. 3, pp. 764-771, 2006.

[30] F. L. Powell and N. Garcia, "Physiological effects of intermittent hypoxia," High Altitude Medicine and Biology, vol. 1, no. 2, pp. 125-136, 2000.

[31] C. E. Norton, N. L. Jernigan, N. L. Kanagy, B. R. Walker, and T. C. Resta, "Intermittent hypoxia augments pulmonary vascular smooth muscle reactivity to NO: regulation by reactive oxygen species," Journal of Applied Physiology, vol. 111, no. 4, pp. 980988, 2011. 
[32] B. Fuchs, N. Sommer, A. Dietrich et al., "Redox signaling and reactive oxygen species in hypoxic pulmonary vasoconstriction," Respiratory Physiology and Neurobiology, vol. 174, no. 3, pp. 282-291, 2010.

[33] R. E. Nisbet, A. S. Graves, D. J. Kleinhenz et al., "The role of NADPH oxidase in chronic intermittent hypoxia-induced pulmonary hypertension in mice," The American Journal of Respiratory Cell and Molecular Biology, vol. 40, no. 5, pp. 601609, 2009.

[34] J. M. Dopp, N. R. Philippi, N. J. Marcus et al., "Xanthine oxidase inhibition attenuates endothelial dysfunction caused by chronic intermittent hypoxia in rats," Respiration, vol. 82, no. 5, pp. 458467, 2011.

[35] A. A. El Solh, R. Saliba, T. Bosinski, B. J. B. Grant, E. Berbary, and N. Miller, "Allopurinol improves endothelial function in sleep apnoea: a randomised controlled study," European Respiratory Journal, vol. 27, no. 5, pp. 997-1002, 2006.

[36] I. Al Ghouleh, N. K. H. Khoo, U. G. Knaus et al., "Oxidases and peroxidases in cardiovascular and lung disease: new concepts in reactive oxygen species signaling," Free Radical Biology and Medicine, vol. 51, no. 7, pp. 1271-1288, 2011.

[37] U. Förstermann, "Nitric oxide and oxidative stress in vascular disease," Pflügers Archiv, vol. 459, no. 6, pp. 923-939, 2010.

[38] S. Aggarwal, C. M. Gross, S. Sharma, J. R. Fineman, and S. M. Black, "Reactive oxygen species in pulmonary vascular remodeling," Comprehensive Physiology, vol. 3, no. 3, pp. 10111034.

[39] E. Panzhinskiy, W. M. Zawada, K. R. Stenmark, and M. Das, "Hypoxia induces unique proliferative response in adventitial fibroblasts by activating PDGFbeta receptor-JNK1 signalling," Cardiovascular Research, vol. 95, no. 3, pp. 356-365, 2012.

[40] S. Li, S. S. Tabar, V. Malec et al., "NOX4 regulates ROS levels under normoxic and hypoxic conditions, triggers proliferation, and inhibits apoptosis in pulmonary artery adventitial fibroblasts," Antioxidants and Redox Signaling, vol. 10, no. 10, pp. 16871697, 2008.

[41] C. Berry, C. A. Hamilton, M. J. Brosnan et al., "Investigation into the sources of superoxide in human blood vessels: angiotensin II increases superoxide production in human internal mammary arteries," Circulation, vol. 101, no. 18, pp. 2206-2212, 2000.

[42] P. J. Pagano, Y. Ito, K. Tornheim, P. M. Gallop, A. I. Tauber, and R. A. Cohen, "An NADPH oxidase superoxide-generating system in the rabbit aorta," The American Journal of Physiology, vol. 268, no. 6, pp. H2274-H2280, 1995.

[43] H. D. Wang, P. J. Pagano, Y. Du et al., "Superoxide anion from the adventitia of the rat thoracic aorta inactivates nitric oxide," Circulation Research, vol. 82, no. 7, pp. 810-818, 1998.

[44] B. Somoza, M. C. González, J. M. González, F. Abderrahim, S. M. Arribas, and M. S. Fernández-Alfonso, "Modulatory role of the adventitia on noradrenaline and angiotensin II responses: role of endothelium and AT2 receptors," Cardiovascular Research, vol. 65, no. 2, pp. 478-486, 2005.

[45] J. Chao, J. G. Wood, V. G. Blanco, and N. C. Gonzalez, "The systemic inflammation of alveolar hypoxia is initiated by alveolar macrophage-borne mediator(s)," The American Journal of Respiratory Cell and Molecular Biology, vol. 41, no. 5, pp. 573$582,2009$.
[46] D. L. Burke, M. G. Frid, C. L. Kunrath et al., "Sustained hypoxia promotes the development of a pulmonary arteryspecific chronic inflammatory microenvironment," The American Journal of Physiology, vol. 297, no. 2, pp. L238-L250, 2009.

[47] J. Zhang, J. M. Patel, Y. D. Li, and E. R. Block, "Proinflammatory cytokines downregulate gene expression and activity of constitutive nitric oxide synthase in porcine pulmonary artery endothelial cells," Research Communications in Molecular Pathology and Pharmacology, vol. 96, no. 1, pp. 71-88, 1997.

[48] S.-Y. Lam, Y. Liu, K.-M. Ng et al., "Chronic intermittent hypoxia induces local inflammation of the rat carotid body via functional upregulation of proinflammatory cytokine pathways," Histochemistry and Cell Biology, vol. 137, no. 3, pp. 303-317, 2012. 


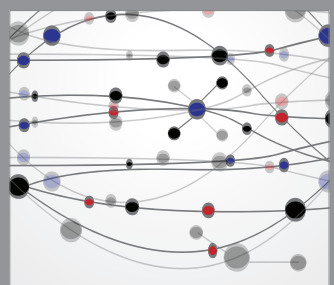

The Scientific World Journal
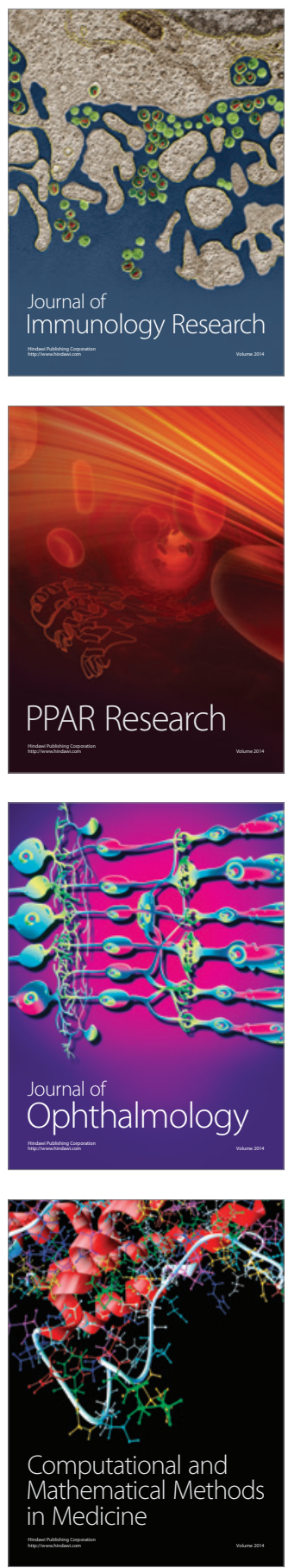

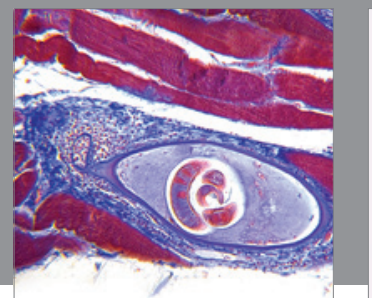

Gastroenterology

Research and Practice
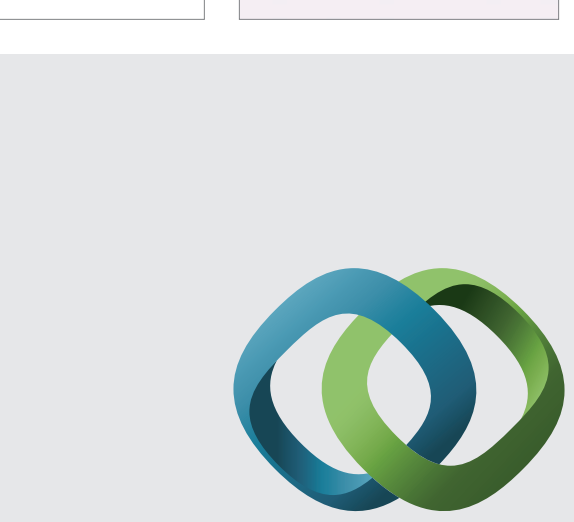

\section{Hindawi}

Submit your manuscripts at

http://www.hindawi.com
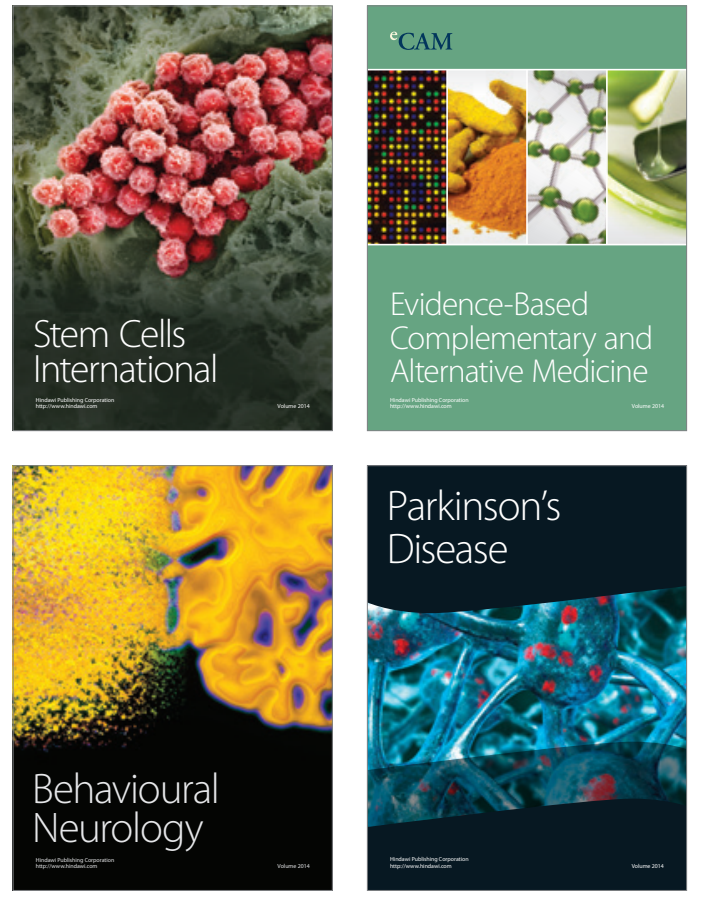
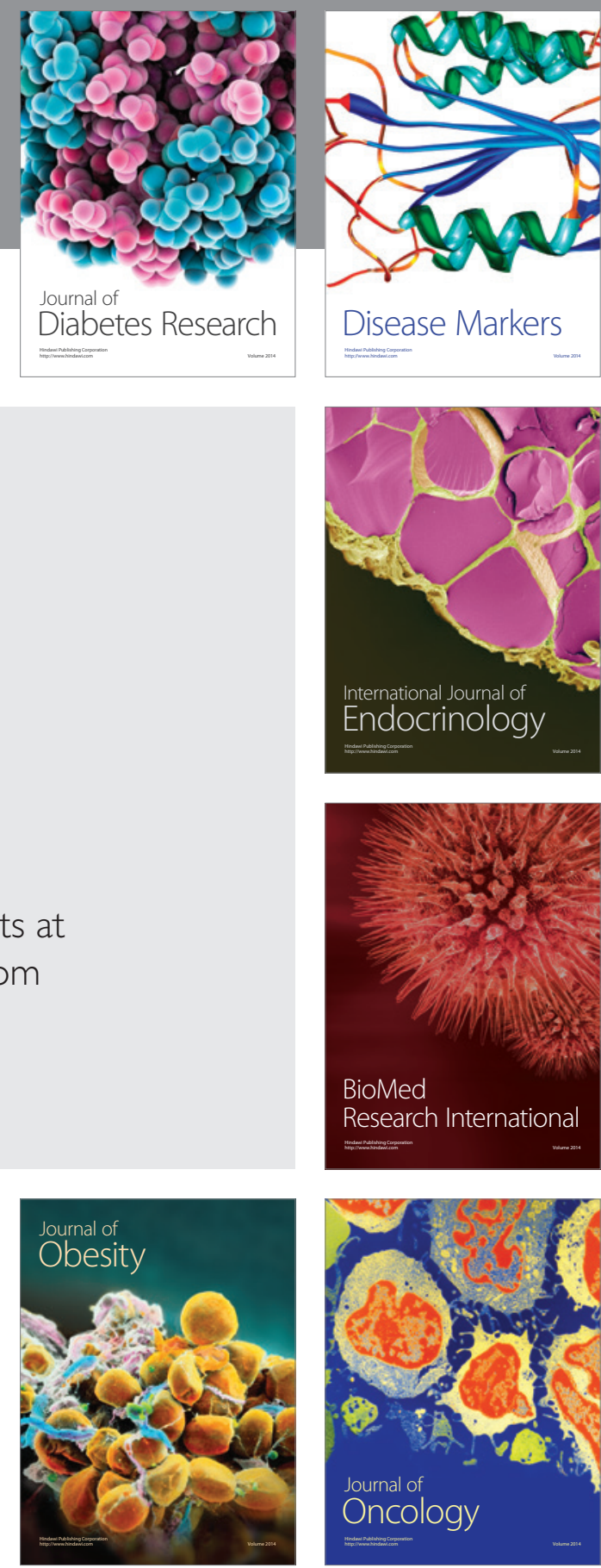

Disease Markers
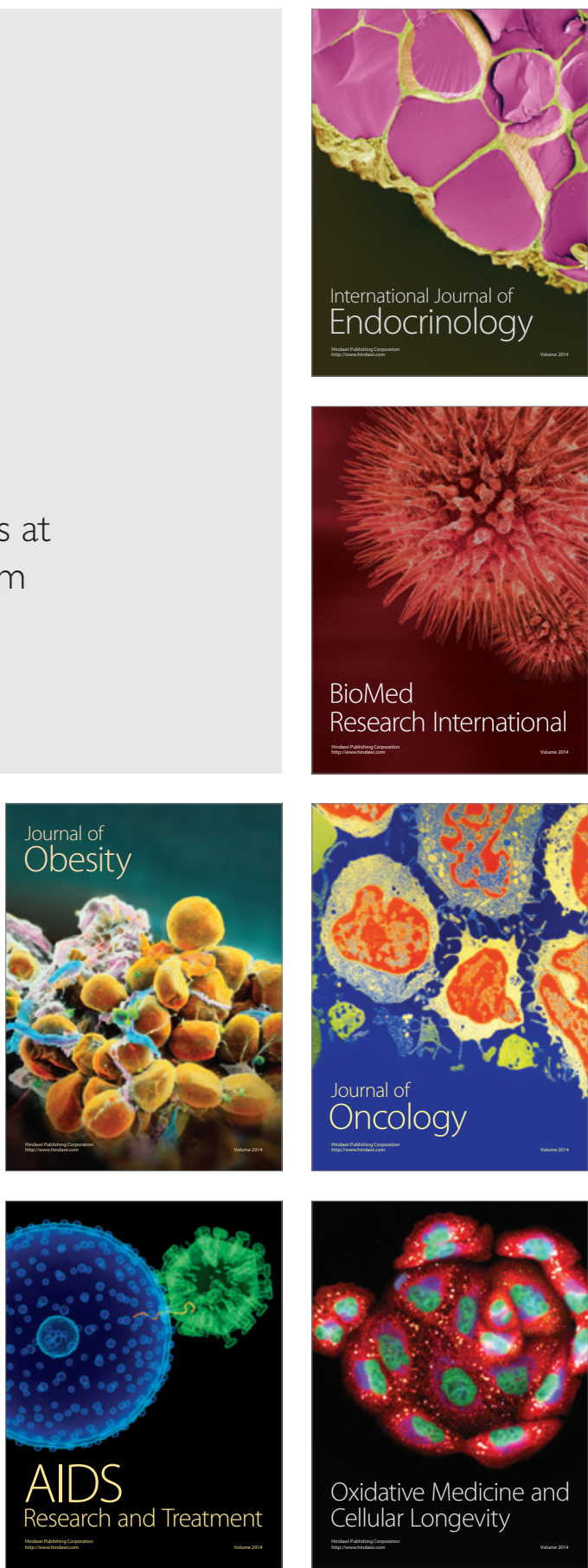